\title{
Stakeholder Management on Construction Projects: A Key Indicator for Project Success
}

\author{
Joseph Ignatius Teye Buertey ${ }^{1,}$, , Daniel Amofa ${ }^{2}$, Felix Atsrim ${ }^{1}$ \\ ${ }^{1}$ Department of Built Environment, Pentecost University College, Kaneshie, Accra, Ghana \\ ${ }^{2}$ Department of Project Management, Accra Institute of Technology, Private Mail Bag, Accra, Ghana
}

Email address:

jbuert@yahoo.co.uk (J. I. T. Buertey)

${ }^{*}$ Corresponding author

\section{To cite this article:}

Joseph Ignatius Teye Buertey, Daniel Amofa, Felix Atsrim. Stakeholder Management on Construction Projects: A Key Indicator for Project Success. American Journal of Civil Engineering. Vol. 4, No. 4, 2016, pp. 117-126. doi: 10.11648/j.ajce.20160404.11

Received: April 27, 2016; Accepted: May 9, 2016; Published: May 27, 2016

\begin{abstract}
Participation is now an international agenda for ensuring full representation of people in terms of their ideas, feeling and decision on matters concerning their development. It has been observed that most projects fail after implementation not due to poor execution but rather due poor stakeholder consultation and engagement. The purpose of this study was to determine the barriers to stakeholder involvement in developmental projects at the grassroots level and examine the impact of stakeholder involvement on the success of projects implemented. Data was gathered through structured questionnaires distributed to ordinary citizens, community leaders and local authority staff in selected district assemblies in Ghana. Analysis of structured questionnaires revealed that there was inadequate explanation of the background, technical and material justification for the project to the stakeholders prior to project initiation. Stakeholders held that they had difficulty in participating in technical discussions and there was the perceived unwillingness of project implementers to involve them during decision making, to this end, the impact of stakeholders towards project success was significant. To overcome the challenge of stakeholder involvement and meaningful impact to projects, stakeholders must develop capacities to contribute meaningfully in discussions or delegate their concerns to professional representatives. To this end, projects implementers must acknowledge the value of stakeholders and embark on stakeholder outreach to solicit their involvement for enhanced project success.
\end{abstract}

Keywords: Stakeholder Involvement, Project Success, Development, Local Government, Communication, Community

\section{Introduction}

The project stakeholder is sine qua non for the measuring of project success. According to [1], stakeholders are individuals and organisations actively involved in the project, or whose interest may be affected as a result of the project execution or completion. Due to the interest of stakeholders on the project, they may exert influence on the project's objective and outcomes. To ensure a successful project, the project team must identify and engage all stakeholders, determine their requirements and expectation and manage their influence in relation to their requirements. Amponsah [2] postulates that Ghana as any developing country has been recording failure in most of their development projects attributable to poor stakeholder engagement. It is further argued that [3] and [4] holds that project failure is strongly related to stakeholders' perception of a project and their involvement in it.

The purpose of this study was to review the extent to which project actors (executors) intrinsically manages their stakeholders, identifying impediments to their involvement in project execution and expatiate solutions and innovations to guide and positively influence daily practice of stakeholder involvement for development at the local level. The results would enable the leaders at the lower level to be more aware of the extent of stakeholder involvement and to find the appropriate steps in involving them much more. Furthermore, the result of the study is also beneficial to the stakeholders at the district level so that in future projects, they will make themselves available for project planning and 
implementation. This will ensure that they are made part of the decision of choosing projects for the community and effectively support the project and improve the acceptance criteria for the project. In other words, organizations can anticipate what their stakeholder's reaction to the project is likely to be so that they can build into the plan of action to win the stakeholders involvement.

Stakeholder literature has offered various conceptualizations and descriptions. According to [5], a stakeholder is a person, group or organization that has interest or concern in an organization. Ward and Chapman [6] postulates that "voluntary stakeholders bear some form of peril as a consequence of having invested some form of capital, human or financial, something of value, in a firm. Involuntary stakeholders are placed at risk as an outcome of a firm's activities. But without the constituent of risk there is no stake". Thus stakeholders have an interest in the actions of an organization and have the ability to influence it. Others like [7] expatiate on the need to emphasize the authenticity of stakeholder relationships in the stakeholder definition as: having some legitimate, non-trivial relationship with an organization, such as exchange transactions, action impacts, and moral responsibilities. This description highlights the environment of relationships between stakeholders and the organization.

The relationships between stakeholders and firms have also been distinct either more broadly or more intently. These views approve a strategic perspective and emphasize the fact that companies have only limited resources and imperfect time that they can spend on dealing with their stakeholders. Therefore, it is in the concentration of management to categorize and pay attention to those stakeholders who have significance on organizations economic interests. Stakeholders can also be defined through their casual relationships and moral claims towards the business. These views regarded as the growth and sustainment of moral relationships with stakeholders as the firm's responsibility. Studies have suggested a diversity of stakeholder classification schemes. Altman [7] mentions that stakeholders can be classified as either claimants or influencers and consider the potential of stakeholders to threaten or cooperate with the organization. Stakeholders can also be separated into internal and external stakeholders, or primary or secondary stakeholders. Internal stakeholders are, for example, employees, customers and shareholders, while examples of external stakeholders are community activists, media, advocacy groups and other non-governmental organizations [8]. Secondary stakeholders are not directly connected with the crucial business because they lack a "formal contractual bond with the firm" or "direct legal authority" over the firm. However, primary stakeholders, such as employees and customers, are in an undeviating association with the firm, indulged in transactions with the firm or have direct legal authority over the firm. In turn, secondary stakeholders are not directly engaged with economic activity, but are still able to impact an organization. Moral and legitimate claims are often emphasized in correlation with less important stakeholders.

Differently stated, [8] however held that stakeholders may also been separated into strategic and moral stakeholders. Strategic stakeholders are measured to be able to impose decisions on the firm, thus the management of their interests is essential. Moral stakeholders are those who are rather affected by the firm. Other works however disagrees with earlier stakeholder conceptualizations and categorizations for uncertainty and suggests that a difference should be made between stakeholders, stake watchers and stake keepers. In terms of classification, stakeholders are those who have a tangible and real stake in a company. Stake watchers, in turn, do not actually have a stake themselves but they guard the interests of actual stakeholders. Examples of stake watchers are unions and community pressure groups. Finally, [8] postulates that stake keepers are the autonomous regulators who have no stake in the firm but have influence and control, such as governments, regulatory agencies and certification organizations [9].

\section{Empirical Review}

\subsection{Stakeholder Involvement in Developmental Projects}

The role of the stakeholders is to produce a system that best meets their needs, be willing to work with others, particularly those outside your chosen specialties, share all information, including "work in progress", and to actively expand their knowledge and skills. It can be upheld that the role of project stakeholders may include but not limited to: provide resources (time, money, etc.) to the project team, educate project implementers about their community, spend time to provide and clarify requirements, be specific and precise about requirements, make timely decisions with respect to project implementers assessment of cost and feasibility, review and provide timely feedback regarding relevant work artifacts of project implementers and promptly communicate changes to requirements [5]. These roles effectively define the relationship between project team and its stakeholders, a relationship that must be honored for a project to be successful.

The quantity of alternatives to top-down governance is myriad; however, participation of stakeholders in all stages of projects (agenda setting, policy formulation, decision making, policy implementation, policy evaluation) appears to have gained extensive endorsement [9]. Stakeholder involvement is a procedure which captures both specialist and lay knowledge in project management. Although many shades of participation exist, it is noteworthy that all forms embrace one kind of stakeholder involvement or another. The critical question is which variety of stakeholder involvement is appropriate for a particular setting and what level of intensity is deemed sustainable [10]. Numerous researchers argue for instance that stakeholder involvement can improve project management process [11]. Another school of thought questions this assertion and suggests that stakeholder involvement is not necessarily an improvement on the 
original top-down governance approach. It cannot be overemphasized that stakeholder involvement requires consensus-building, negotiation, conflict resolution, tradeoffs and holistic thinking and these issues are frequently time consuming and expensive, irrespective of the scale [10]. The opposing views in the on-going debate imply that there is the need to look at the issues at stake from the arena of complexity since either way, a mere reversal of governance approach seems to be insufficient to tackle multi-dimensional problems.

In the case of stakeholder involvement in projects, this is instrumental in the sense that it is a means to an end. The end or goal is behavioural change on the part of the stakeholders. It is however simplistic to assume that information access through stakeholder involvement will necessarily translate into behavioural change. Regardless of one's position on the matter, it seems evident that a certain gauge for evaluation is necessary to inform the position an individual takes on the success or failure of the participatory process. According to [12], any kind of evaluation has to capture either the process goals or the outcome goals. An evaluation which focuses on process goals may consider the participatory exercise triumphant if the socio-economic dissimilarity gap is bridged. At the same point in time, an assessment which focuses on result goals may see the exercise as ineffective because the project was a disappointment. In either case, the conclusion is subjective because it hinges on the values of the individual conducting the assessment. Owing to the malfunction of development projects in the 1950s and 1960s, social workers and field activists began to call for the inclusion of populations concerned with development in project design and implementation [13]. The perception then was that such projects were ineffective because local populations were left out of the decision making process; a state of affairs that tended to perpetuate social inequality. Hence stakeholder involvement was proposed as an apparatus to uphold equality through empowerment inclusion. Remarkably, even though stakeholder interest was projected to address inequality, the literature is stuffed with cases where it instead perpetuated inequality [14].

Central to the course of participation is the issue of mediation, which involves a discursive and impulsive connection between the law and democracy [15]. According to [16], the concept of discursive democracy within which stakeholder involvement resides, is becoming the normal practice in the management of projects. The conjecture of discursive democracy transcends forthcoming action as it encapsulates a theory of law and democratic institutionalization. The theory considers 'democracy as not being ingrained in civic society or popular autonomy, but in the structures of communication, for which Habermas takes for granted the prospect of consensus and argumentative discourse' [15]. In discursive democracy, equal access to the discursive platform is a fundamental notion [16]. However, [17] argues that this assumption in reality may not always be the case. For instance, in Ghana, the history of stakeholder involvement shows that this is not the case [8]; therefore, effective monitoring of the involvement process is indispensable to ensure equivalent entree to the discursive territory.

Delanty [16] argues that Habermas perceives popular or representative democracy as inadequate in grasping the complications in modern plural societies. In the same vein, it is also argued that popular democracy fails to 'take account of the actuality of multi-cultural pluralism, which challenges both the concept of unity of the civic community and the appeal to legitimacy on the basis of popular sovereignty' [15]. These shortcomings of popular democracy underpin Habermas' proposal of the theory of discursive democracy of participation. The theory is noteworthy for a number of motives. First, it recognizes the authenticity of multi-cultural value systems. Next, it takes into account the problem of complication in modern societies. Finally, it identifies the question of law and institutionalization [17]. In essence therefore, the theory of discursive democracy of stakeholder participation takes into account both agency (of individuals to make decisions) and structure (the establishment of new institutions through participatory practice) [15].

\subsection{Stakeholder Involvement in Different Stages of Projects}

Development projects often start through multiple stages in which different stakeholders may be involved [18]. Active stakeholders have a significant influence in the community and on the project, make choices that directly affect others, and are necessary for recruiting other stakeholders. In contrast, passive stakeholders are influenced by the choices of active stakeholders. Primary stakeholders are active decision makers that have great influence in the community and also on the project, and must be involved in all the project stages. Secondary stakeholders are mostly passive, undertaking decisions made by primary stakeholders and have little influence during the implementation phase.

The planning and design stages of projects which is supposed to be the most important phase, paradoxically involve only few stakeholders and are most often the project gatekeepers. This phase of the project interestingly takes the shortest duration, mostly neglecting the primary stakeholders. The implementation stage mostly involves almost all the key stakeholders including the primary stakeholders. The monitoring and evaluation stage of developmental projects, which is an evolving stage of the implementation phase include all stakeholders involved in the prior stages in an attempt to gauge the long-term success of the project, generally ensuring that most stakeholders are considered and encourages their active involvement in the project [19]. Though stakeholder involvement must not be fixed or rigid, identifying where and how their input is needed, is necessary particularly in multi-stakeholder projects as it is not possible or practicable to involve all stakeholders passionately at every stage of the project. While it is not all stakeholders that have the same power and influence, it is believed that it is crucial to identify at the early stages of the project, the primary 
stakeholders who exert most influence and are most significant to the efficient project completion [20].

\subsection{Factors That Influence Stakeholder Involvement in Development Projects}

Many dissimilar forces are at work, proceeding to, and throughout, a public partaking programme, with intrinsic features moving following features have moved the participatory deliberation forward. People generally resist change, especially when they do not comprehend or approve to the goals, the devices, the sponsor or the timing of the anticipated change. So, keeping the public in the dark is often a recipe for disaster [21]. The citizens are also progressively unenthusiastic to defer to 'expert' government agency opinions, and are unwilling to act as sounding boards for bodies that have already made decisions, particularly when they affect their local communities [22]. These tendencies lead to a lack of public buoyancy and trust, except the relevant authorities take note of them. A far-reaching programme ensued, based on meaningful involvement and fair management for all races, cultures and incomes in project decision-making. The transmittance of 'experience', rather than knowledge, is the critical neglected dimension of decision-making, particularly as it relates to project decision-making [23]. The further the project implementation is from stakeholders, the more pertinent becomes the public participation in same, and in this context, face-to-face meetings are critical to producing real learning and trust.

Jergeas et al., [24] found two factors that influence stakeholder's involvement in development projects; communication and setting common goals, objectives and project priorities. Effective communication is very vital for getting the support and commitment of stakeholders [25]. Regular communication with members of the project community is very important for effective project performance [26]. According to [27], the performance of development projects and its ability to satisfy stakeholders is dependent on decisions that are made and the care taken by policy-makers in stakeholder communication. In the view of [28] the key issue in project stakeholder involvement is about managing and promoting the friendship and relationship between the project and its stakeholders. It can be held that successful relationships between stakeholders and the project are important for successful implementation of projects. Trust and commitment between project implementers and stakeholders can be developed and sustained through an effective relationships management [19].

\subsection{Benefits of Stakeholder Involvement in Project Implementation}

The actualization of project goals and the improvement of projects benefits to the community is the focal aim of stakeholder participation in projects. It is intended to advance the quality of both the procedure and the end decision. The participation process is also a learning curve for all the stakeholders involved, particularly if there is an unrestricted flow of information between the parties. For the public it can often be the first experience of taking a vigorous part of the project implementation process. Projects benefit from the direct and immediate knowledge held by citizens and business, concerning project implementation environmental in their communities. Encouraging the public and other stakeholders to share their knowledge, with the regulatory authorities, fosters better-informed decisions and decreases the likelihood of project failure. Out of the 25 overseas projects sponsored and evaluated by the World Bank, 13 failed mainly as a result of lack of local input [29]. It should be realized that wisdom is not limited to scientific specialists and government officials, and that rational analysis carried on in ignorance of political reality, may well end up so divorced from social reality, hence may be of little use to anyone [23].

Stakeholder involvement gives broader perspectives on a particular process, and early involvement gives added time to study issues and develop the process, enhances credibility of the decision making process, fosters early identification of the diverse perspectives on the issues of concern and the generation of solution options [29]. Better-designed projects, which avoid costly delays in appraisal and implementation, can also result from early and planned consultations and stakeholder involvement [30]. For the proponent, early stakeholder involvement can have the added benefit of diffusing opposition to a project. If a broad based consensus is built, it can also lead to a public sense of 'ownership' [31]. The public's enthusiasm is potentially a powerful motivating force for project implementation. Stakeholder involvement can also supplement scarce government monitoring, inspection, enforcement and resources [30]. Stakeholder involvement in projects is a learning experience which gives the public insight into the governance process. If the experience is good, it powers the way for future co-operation. The converse can also be true.

\subsection{Problems Encountered in Stakeholder Involvement in Project Implementation}

There is limited information on the relative costs of using the different methods of stakeholder involvement practice, although some attempt is made to quantify it. Actual costing for specific processes are given in a number of studies [32]. Clearly deliberative processes which are used to engage relevant stakeholders in debate, discussion and deliberation, could only be done as part of another research. The intensity of the stakeholder process, including commitments of time, energy and money, and often, uncertain results, has led to a burnout phenomenon amongst many participants, and from all stakeholder groups [33].

Excessive raised expectations about Stakeholder involvement can lead to frustration and anger with a breakdown in trust. It is essential then to be clear with all participants as to the limits of influence of the process. Where an infrastructure project crosses planning jurisdiction boundaries or where more than one official is involved, the costs to the public, state and advocates are multiplied. The 
amplified time scale and disbursement involved in stakeholder involvement is of particular worth in projects with a small capital funding. The foremost areas of struggle affecting stakeholder involvement are attitudinal, lack of capability to deliver programmes, lack of clarity about what outcomes are possible and the lack of a legislative framework. The challenge of accessing the necessary resources for a worthwhile stakeholder public participation process, whether by the advocate or the regulator, by the commitment of personnel and finances, is essential. The repercussions for project proponents, of not having a properly planned and funded participatory project process, may prove much costlier than dealing with the backlash. In many circumstances, the choice increasingly is not whether to involve the public, but how to get the best value from the chosen process [32]. To avoid hearing from only the activist or the powerful elite, and in order to get the widest sweep of opinion and information, authorities must reach out into the community [34]. In this regard some activities are best avoided, for example public meetings. In the absence of trained facilitators these can often come down to 'he who shouts loudest wins!'

Some institutions resist change, and communication blocks within stakeholders can prevent them from making head way. The established routines and organizational systems of many bodies seek to promote the 'status quo'. Organizational structures which support sustainability, and therefore public participation, are a threat to 'command and control' style management systems. Managers, who have risen to power in this style of structure, frequently resist the transition to alternative structures, which embrace public consultation [35]. Many opportunities for stakeholder participation are laid down in the environmental permissible framework, where legislation does not specify early stakeholder involvement, then it is at the discretion of the relevant authority, and dependent on the opinion of the relevant public servant. For example, in the growth planning process, the Manager's reporting of the consultative process clearly includes the names and nature of all submissions together with his response to them.

\section{Methodology}

The study population involved the people of the Ada East and Gomoa East District Assemblies specifically the assembly members, community members and the District Planning Coordinating Unit. A sample size of ninety (90) was determined using statistical of Kumar [36] methods. A structured questionnaire using both open-ended and closedended questions were developed and administered by hand delivery to respondents, yielding a response rate of $69 \%$. In cases where the responses to a question were unlimited and could not be adequately answered with few words, or where the responses concerned qualitative and opinion related issues, open ended questions were used to capture the response. This facilitated large collection of data within the shortest possible time. It also provided the opportunity for respondents to express their opinions and views. The questionnaire was designed to cover complete assessment and understanding of the phenomenon under investigation with the following main objectives:

- Understand the factors/barriers that influence/affect the stakeholder involvement process in development projects?

- Examine the impact of stakeholder involvement on the performance (success or failure) of projects implemented?

- Recommend ways of improving stakeholder participation in the decentralization process in Ghana?

\section{Analysis and Discussion of Data}

The quantitative data was analysed based on the five-point scale ratings provided by the respondents on separate categories. These ratings were combined to deduce the relative importance indices of the factors based on respondents ratings, after which further analysis were made to compute the overall weightings and interpretations based on respondent's view on barriers to stakeholders involvement, and how to improve stakeholders involvement based on the total sample size. The significance testing was used to decide whether to accept or reject the null Hypothesis, Ho. An evaluation of the test statistics (X) was done and the probability (P-Value) of observing a value of the test statistics was also determined. The $P$ value was taken as the smallest value at which the significance level $(\alpha)$ could be present and still have small (lesser than 5\%) significance level.

The sample mean for the data in respect of each factor and the effect of variation are shown in the table 1 . The 5-point rating (1, 2, 3, 4 and 5) have mean of 18 and varying standard was used based on varying dispersion of respondents' view. The $p$-value for the test was determined to find out if there was much difference between the null value of $\mu=18$, and the sample means in table 2 to cause the rejection of the Ho. The profitability of observing the sample mean or larger $\mu=18$ and $\sigma$ was computed. The test statistics $(\mathrm{X})$ was the central limit theorem, where $\mathrm{x}$ is approximately normally distributed with mean $\mu$ and Standard Deviation, $\sigma / \sqrt{ } \mathrm{n}$ where $\mathrm{n}=$ number of responses for that factor. The p-value was obtained using the relation below.

$$
P=(x \geq \mu)=p\left(z \geq \frac{x-\mu}{\frac{\sigma}{\sqrt{n}}}\right)=1-P\left(z \leq x-\frac{\mu}{\frac{\sigma}{\sqrt{n}}}\right)
$$

From the cumulative distribution standard normal table, where $\mathrm{Fz}(\mathrm{z})=\mathrm{P}[\mathrm{Z} \leq \mathrm{z}]$, the value of $\mathrm{z}$ ranges form -3.9 to 3.9. Any value of $z$ less than -3.9 has a Fz (z) of zero (0) whereas vales of more than 3.9 has $\mathrm{Fz} \mathrm{(z)}$ of unity (1).

The $\mathrm{P}$ value is the smallest level of significance for which the observed data would call rejection of Ho in favor of $\mathrm{H}_{1}$. The $\mathrm{P}$ value gives additional insight into the strength of the decision taken. Thus a relatively small $p$-value of 0.001 indicates that there is little likelihood that Ho is true. On the 
other hand a high p- value such as 0.2033 means that Ho is not rejected and there is little likelihood that it is false.

The P-value is often referred to as the observed level of significance for a given level of significance, $\alpha$

Reject Ho if $\mathrm{p}$-value $\leq \alpha$

Do not reject Ho if $\mathrm{p}$-value $>\alpha$

Thus the larger population has a distribution of $\mathrm{P} \sim \mathrm{X}[\mu=$ $18, \sigma=\mathrm{x}]$

For example the P- value for 'inadequate explanation of background and technical material is calculated as follows

$$
\mathrm{P}[\mathrm{X} \geq 4.696]=\mathrm{p} \frac{[307-18]}{\left(\frac{7.2}{\sqrt{90}}\right)}
$$

$$
\mathrm{P}[\mathrm{Z} \geq 1.859]=0.0955
$$

Since the null hypothesis $\mathrm{Ho}=0.05<0.09550$, we accept Ho, thus the factor 'inadequate explanation of background and technical material' is an important factor affecting stakeholder involvement in project.

\begin{tabular}{|c|c|c|c|c|c|c|c|c|c|c|c|c|c|c|}
\hline No & Descriptors & 1 & 2 & 3 & 4 & 5 & $\begin{array}{l}\text { Rel } \\
\text { Imp }\end{array}$ & Weight & Rank & Mean & SD & $\begin{array}{l}\text { VAR } \\
(\sigma)\end{array}$ & $\begin{array}{l}\text { STAND } \\
\text { (P1) }\end{array}$ & $\begin{array}{l}\text { p- } \\
\text { value }\end{array}$ \\
\hline A & \multicolumn{14}{|c|}{ Respondents view on barriers to stakeholders involvement } \\
\hline A1 & $\begin{array}{l}\text { Inadequate explanations of } \\
\text { background and technical material? }\end{array}$ & 12 & 15 & 12 & 27 & 24 & 307 & 0.682 & 4 & 18 & 51.84 & 7.2 & 1.85 & 0.0955 \\
\hline $\mathrm{A} 2$ & $\begin{array}{l}\text { Poor Accountability on the part of } \\
\text { implementers }\end{array}$ & 6 & 28 & 15 & 29 & 12 & 282 & 0.626 & 7 & 18 & 99.63 & 9.94 & 1.62 & 0.9475 \\
\hline A3 & $\begin{array}{l}\text { Inadequate stakeholder consultative } \\
\text { meetings }\end{array}$ & 18 & 23 & 27 & 11 & 11 & 243 & 0.540 & 9 & 18 & 53.46 & 7.31 & 2.05 & 0.0202 \\
\hline A4 & $\begin{array}{l}\text { Perceived inability to influence } \\
\text { issues }\end{array}$ & 12 & 11 & 18 & 26 & 23 & 307 & 0.684 & 3 & 18 & 44.418 & 6.9 & 2.55 & 0.1100 \\
\hline A5 & Lack of time to participate? & 11 & 38 & 22 & 12 & 8 & 239 & 0.530 & 10 & 18 & 148.63 & 12.1 & 1.22 & 0.0131 \\
\hline A6 & $\begin{array}{l}\text { Failure to incorporate stakeholders } \\
\text { view during scope definition }\end{array}$ & 25 & 22 & 18 & 14 & 11 & 234 & 0.520 & 12 & 18 & 32.5 & 5.7 & 2.58 & 0.0561 \\
\hline A7 & $\begin{array}{l}\text { Poor communication between } \\
\text { implementers and users (challenges } \\
\text { in accessing information) }\end{array}$ & 11 & 22 & 21 & 15 & 21 & 283 & 0.629 & 6 & 18 & 23 & 4.8 & 3.39 & 0.8641 \\
\hline A8 & $\begin{array}{l}\text { Lack of Technical capacity and } \\
\text { support on the part of stakeholders }\end{array}$ & 16 & 13 & 15 & 24 & 22 & 293 & 0.651 & 5 & 18 & 22.5 & 4.74 & 3.50 & 0.9970 \\
\hline A9 & $\begin{array}{l}\text { Inability of project implanters to } \\
\text { identify all stakeholder }\end{array}$ & 39 & 21 & 15 & 5 & 10 & 196 & 0.436 & 13 & 18 & 173 & 13.2 & 1.01 & 0.0846 \\
\hline A10 & $\begin{array}{l}\text { Low enthusiasm on the part of the } \\
\text { local stakeholders (apathy) }\end{array}$ & 22 & 22 & 15 & 14 & 17 & 252 & 0.560 & 8 & 18 & 14.5 & 3.81 & 4.02 & 0.0537 \\
\hline A11 & Feeling of powerlessness & 10 & 11 & 19 & 25 & 25 & 314 & 0.698 & 2 & 18 & 53 & 7.28 & 2.36 & 0.9960 \\
\hline A12 & $\begin{array}{l}\text { challenge of accessing resources to } \\
\text { enhance stakeholder efficiency }\end{array}$ & 27 & 15 & 16 & 21 & 11 & 244 & 0.542 & 11 & 18 & 38 & 6.16 & 2.44 & 0.0997 \\
\hline A13 & $\begin{array}{l}\text { Unwillingness of project } \\
\text { implementers to involve } \\
\text { stakeholders? }\end{array}$ & 7 & 11 & 25 & 14 & 33 & 325 & 0.722 & 1 & 18 & 115 & 8.3 & 1.63 & 0.2500 \\
\hline B & \multicolumn{14}{|c|}{ How to improve stakeholder involvement in projects } \\
\hline B1 & $\begin{array}{l}\text { Stakeholders must develop their } \\
\text { capacities to contribute meaningfully } \\
\text { to project discussion? }\end{array}$ & 2 & 5 & 2 & 26 & 55 & 397 & 0.882 & 3 & 18 & 527.715 & 23 & 0.85 & 0.8023 \\
\hline B2 & $\begin{array}{l}\text { Project implementers must adopt the } \\
\text { use of technology to improve } \\
\text { stakeholder involvement? }\end{array}$ & 2 & 7 & 5 & 40 & 36 & 371 & 0.824 & 4 & 18 & 332.1 & 18.2 & 1.03 & 0.8707 \\
\hline B3 & $\begin{array}{l}\text { Project implementers must embark } \\
\text { on stakeholder outreach to solicit for } \\
\text { their involvement? }\end{array}$ & 2 & 4 & 1 & 34 & 49 & 394 & 0.879 & 2 & 18 & 496.4 & 22.5 & 0.87 & 0.1920 \\
\hline B4 & $\begin{array}{l}\text { Project implementers must } \\
\text { acknowledge the value of } \\
\text { stakeholders towards the success of } \\
\text { projects? }\end{array}$ & 1 & 2 & 2 & 23 & 63 & 415 & 0.922 & 1 & 18 & 715.63 & 26.8 & 0.74 & 0.2200 \\
\hline $\mathrm{C}$ & \multicolumn{14}{|c|}{ Respondents view on projects implemented in the community } \\
\hline $\mathrm{C} 1$ & $\begin{array}{l}\text { Are projects implemented needed by } \\
\text { the community? }\end{array}$ & 5 & 7 & 22 & 20 & 36 & 344 & 0.764 & 1 & 18 & 153.9 & 12.4 & 1.45 & 0.3500 \\
\hline $\mathrm{C} 2$ & $\begin{array}{l}\text { How regular are projects } \\
\text { implemented in the community used? }\end{array}$ & 13 & 16 & 14 & 21 & 26 & 302 & 0.670 & 2 & 18 & 29.565 & 5.44 & 3.10 & 0.9900 \\
\hline $\mathrm{C} 3$ & $\begin{array}{l}\text { Will you have preferred other } \\
\text { projects to the current ones? }\end{array}$ & 11 & 16 & 20 & 14 & 29 & 304 & 0.676 & 3 & 18 & 46.98 & 6.85 & 2.47 & 0.1100 \\
\hline
\end{tabular}

Table 1. Statistical analysis of Barriers to stakeholder involvement In community Projects. 
Although participation of stakeholders is seen as critical for the project success, there exist variety of obstacles. To understand the barriers that exist at the district level, a series of questions were developed and administered to respondents. Based on statistical analysis from table 1, it was deduced that the stakeholder opined that the main barrier to their involvement in projects is the unwillingness of project implementers to involve them. With a p-value of 0.0025 , the factor can be deployed as a very significant factor. Using relative importance indices, it was weighted 0.722 and ranked first. It can thus be deduced that most project are initiated without the involvement of the end users. These projects are planned from above by the sponsor or financiers and rolled at the lowest level without seeking their involvement and inputs. The research by [37] [38] and [3] affirms the above that the strongest challenge to stakeholder involvement is recognition, this has been postulated to be the attributor to project failure at the lowest level.

With a p-value of 0.0996 , analysis of field studies revealed that the end usser stakeholders' feeling of powerlessness is a reason for their non-involvement in project executed. This factor was analysed to be second most significant factor affecting stakeholder involvement in projects with a relative importance of 0.698 . The feelings of powerlessness engendered by these hurdles, add to public perceptions of a lack of influence at both lower and higher levels of local development. Consultations of interested parties.... can only ever supplement, and never replace, procedures and decisions of legislative bodies which possess democratic legitimacy. This sense of powerlessness may be part of the reason why, even in cases where considerable energy and resources are expended, to identify individuals and groups, only a small proportion of the public ever attend participation programmes [32]. Stakeholder involvement may actually result in an increased level of conflict. Becoming involved in a consultative process where the decision has already been made, or where the possible outcomes are not made clear at the outset, can lead to a great deal of frustration. Anger may follow when the input of the public is ignored, especially following prolonged constructive engagement. Conflict can also occur between professionals. One source of such disagreements could evolve from the different emphases of 'scientific peer review' and 'social peer review'. The scientific peer review process is well established, and is essential to assess the technical information provided to policy makers. The corresponding social peer review, designed to obtain societal acceptance and legitimacy for the decisions rendered, by contrast, does not have a set of acknowledged professional standards [29]. It should also be remembered that whilst science may strive for the 'truth', the opinions of scientists are colored by their values and beliefs. The resulting deadlock exasperates the capability of planners to accomplish consensus on preliminary issues and contributes to anti-participation attitudes.

Therefore, rather than attitudes as an irrational response to glitches ordinary citizens cannot grasp, the solution is to inspire more participation not less [38]. The misconception that stakeholders are overly emotional, ill-informed and solely encouraged by selfish interests in their impediment of facilities for the common good leads to an information-based strategy, the postulation being that, 'if only stakeholder knew the truth!' This assumes the existence of an objective truth to know [32]. The conflict that arises from having dissimilar bodies making decisions on different parts of the project execution can often confuse the public understanding and increase frustrations.

Closely linked with the second important factor is the perceived inability to influence situation. Analysis of field data revealed that $67 \%$ of respondents indicating their opinions and views shared on how to improve the post implementation usage of the project at stakeholder consultative meetings were neither factored any nor reasons given for declining to adopt them. Thus stakeholders perceive that they have very low ability to influence situations since mostly at the execution stage where they are involved, the scope definition for the project has been sealed. According to [38], public 'hearings' often do not comprise 'listening'. In a research by [39], citizen's efforts and ideas are not included in offers and no reason given. Similarly, public hearings are criticized for: being apprehended at times inopportune for the public, establishing an atmosphere that inhibits negotiation, and conducting proceedings that intimidate the public. The lack of an obviously definite purpose can also mean that the role of the public is every now and then uncertain not only to the public but to those delivering the process, with the significance that the participation process chosen is often unsuitable for the specific project [22].

At $5 \%$ level of significant, the hypothesis 'inadequate explanation and background of technical materials' was tested to be true, with a p-value of 0.0995 . This is closely linked with the fifth most significant factor, 'lack of technical capacity and support on the part of stakeholders. Some significant majority of respondents about (57\%) agreed to the assertion that the barrier to stakeholder involvement was perceived to be linked to their low technical capacity. According to a report by [29], there is a universal lack of experience of partaking processes, and very few stakeholders have experienced planned participation processes. There may be suspicion, cynicism, or lack of enthusiasm, but there is unlikely to be previous training. Suspicion about participation could be from politicians, who may feel their power is being diluted, or from NGOs that have very explicit and stationary viewpoints. Cynicism could be from prior public participation processes which were ill managed, leaving participants unenthusiastic to try again. Stakeholders are exasperated when they are treated as antagonists, rather than comfy participants in the project. Lack of technical support for stakeholders, and difficulties in getting access to information can diminish the ability of the public to play an eloquent part in project processes. Stakeholder access to sovereign expertise in a particular technical/scientific field can prove difficult, particularly where the proponent of a 
project is a monopoly employer. Stakeholders with no technical/scientific experience find it difficult to access, comprehend or evaluate data and information, especially under these short time constraints.

One factor highlighted as significantly important is the poor communication between project implementers and stakeholders. With a p-value of 0.56 , the hypothesis: poor communication is a barrier to stakeholder involvement was tested to be true. Interestingly, over $65 \%$ of respondents indicated that during project execution, communication between the various stakeholders is very poor. This is an indication that there is the need to undertake proper briefing of stakeholders if their involvement is to be felt and not necessarily the provision of adequate minutes. Also it provides practitioners with an idea about the need for circulation of message to the different stakeholder. That is to say the document for an educated person cannot be the same for an uneducated person. Secondary data presupposes that stakeholders have all the time available but implementers just don't involve them or communicate effectively with them. The challenge of poor communication may be seen as a recipe for the poor accountability the stakeholders highlighted. When people are left in the dark, they make all sort of assumption.

On the question of the need, regularity of use and preference to other projects, an overwhelming majority of respondents $(89 \%)$ indicated that projects developed in the district were projects which meets their needs. An approximately $82 \%$ of the respondents to questionnaire administered further held that the projects developed in the community were effectively in use by the community. Interestingly over $58 \%$ of respondents indicated that would have preferred other projects to the current ones.

The above interesting assertion can be explained to mean that though projects executed were important to the local communities, these projects could have been deferred to a later date making way for their actual pressing needs. This interesting scenarios is eminent when governments and people in authority plan for the need of the people at the grassroots without duly engaging them.

On the issue of how to improve stakeholder involvement, solicited and analysed views from stakeholders are skewed towards the need for implementers to acknowledge the value of stakeholders towards project success. At 5\% level of significance, this was tested with a p-value of 0.022 . closely linked to the above is the request for project implementers to embark on stakeholder outreach to solicit views prior to project commencement.

\section{Recommendations and Conclusion}

This study provided evidence to support or dispute earlier studies made into the field of stakeholder involvement in the decentralization process in relation to project planning and implementation. Previous studies have examined stakeholder involvement in project planning and implementation [9], [11] and [13], factors influencing their involvement by [20] and
[25] benefits of stakeholder involvement [20] and [31]. Other studies have also looked into the problems encountered in stakeholder involvement [32] and [38]. The result from this study suggests that stakeholder involvement in project planning and implementation significantly affect the success or otherwise of the project. This confirms earlier research made indicating that community participation in the design and implementation of a project greatly enhances the likelihood of project success. Further studies also indicate that generally, ensuring that stakeholders are considered encourages their active involvement in the project [19]. However, the study indicate that respondents put emphasis on building trust, agreeing on rules of engagement and adhering to advice from stakeholders as critical to the success or otherwise of the project. Thus, even if the involvement would be limited, the little engagement made should be considered important by implementers and the advice from stakeholders incorporated into the process.

The results of the survey conducted indicate that there are varied factors that inhibit the involvement of stakeholders in the development of projects at the district. According to findings, the key barriers that influence stakeholder's involvement in projects were; inadequate explanations of background and technical material and unwillingness of project implementers to involve stakeholders and not the lack of effective communication or regular communication as suggested in the study undertaken by [26] and [27] respectively. The survey data and analysis indicated that although implementers may have regular meetings with stakeholders, there is little attention paid to the advice provided by stakeholders to the project. Another major finding of the study was that it was not project stakeholders who were unwilling to contribute to the process of project implementation but rather due to the unwillingness of project implementers to involve the stakeholder, the perceived inability of stakeholders to influence issues, unwillingness of project implementers to involve stakeholders amongst others. The study also shows that although stakeholder may be involved in planning and implementation, their involvement is limited, since their views to improve the performance of the project was not acknowledged by implementers. A significant proportion of respondents indicated that though projects executed in the community are regularly used by the citizenry, they would have preferred other projects to the current ones.

There is debate in the literature over whether the performance of development projects and its ability to satisfy stakeholders is dependent on decisions that is made and the care taken by policy-makers in stakeholder communication [28] as against building trust amongst stakeholders and implementers. However, it is suggested that all approaches are important given that the data received from the survey indicated that majority of respondents believed that trust building and communication was an issue between stakeholders and implementers. It is often noted in the research that the feelings of powerlessness engendered by these hurdles, add to public perceptions of a lack of influence at both lower and higher levels of local development. 
According to [32], this sense of powerlessness may be part of the reason why, even in cases where considerable energy and resources are expended, to identify individuals and groups, only a small proportion of the public ever attend participation programmes. However the study undertaken proved that not to be the case. A deliberate question was asked targeted at investigating this assertion, however the findings indicated that majority of respondents disagreed with that assertion but rather placed emphasis on the willingness of project implementers.

The results from the analysis of capacity gaps amongst stakeholders confirmed varied studies undertaken which indicate that there is universal lack of experience of partaking processes, with very few stakeholders ever experiencing the planned participation processes. On the other hand, in terms of the ability of stakeholders to comprehend technical documents, the study found out that more than half of respondents interviewed were unable to understand background and technical material of projects and as such found it difficult to evaluate data and information, especially under short time constraints. This constraint was seen as critical in that it was one of the most ranked issue needed for improving stakeholder involvement, with approximately $90 \%$ of respondents stating that it was needed.

To improve stakeholder participation and impact on projects implemented, there is the need for:

- Implementers to consciously identify all stakeholders to the project.

- Project implementers to acknowledge, value and engage these stakeholders

- Enhance communication between the stakeholders

- The application of new technologies to entice and improve stakeholder involvement in project development and implementation.

- Improve the technical capacities and support for the project.

With the improvement of stakeholder participation in projects implemented, the study found out that taking advice from stakeholders was more likely to result in projects been used in economic proportions in the district or community for which the project is implemented.

\section{References}

[1] Project Management Institute (2013). A guide to the project management body of knowledge (5th ed.). Newtown Square, Pennsylvania: PMI Publishing Division.

[2] Amponsah Richard (2012). The Real Project Failure Factors and the Effect of Culture on Project Management in Ghana. ICBE-RF Research Report No. 45/12.

[3] Suer, C. (1993). Why information systems fail: A case study approach. Henley-on Themes, UK: Alfred Waller.

[4] Lemon, W. F., Browitz, J., Burn, J. \& Hackney, R. (2002). Information systems failure. A comparative study of two countries. Journal of Global Information Management, 10 (2), $28-40$.
[5] Achterkamp, M. C., Vos J. F. J., 2008. Investigating the use of the stakeholder notion in project management literature, a meta-analysis. International Journal of Project Management, 26 (7), 749-757.

[6] Ward, B Chapman, A (2008). A stakeholder approach to strategic management. In: Freeman, R. E., Harrison, J. S., (Eds.), the Blackwell Handbook of Strategic Management, Blackwell, Oxford, 189-207.

[7] Aaltonen, K.; Jaakko, K.; Tuomas, O. (2008). Stakeholder salience in global projects, International Journal of Project Management 26: 509-516.

[8] Botchway, K. (2001). Paradox of Empowerment: Reflections on a Case Study from Northern Ghana. World Development, 29 (1), 135-153.

[9] Giordano, R., Passarella, G., Uricchio, G. F., \& Vurro, M. (2007). Integrating conflict analysis and consensus reaching in a decision support system for water resource management. Journal of Environmental Management, 84, 213-228.

[10] Fraser, et al., (2006). Bottom up and top down: Analysis of participatory processes for sustainability indicator identification as a pathway to community empowerment and sustainable environmental management. Journal of Environmental Management, 78, 114-127.

[11] Prager, K., \& Nagel, U. J. (2008). Participatory decision making on agri-environmental programmes: case study from Sachsen-Anhalt. Land Use Policy, 25, 106-115. Germany.

[12] Murdock, B. S., Wiessner, C., \& Sexton, K. (2005). Stakeholder Participation involuntary Environmental Agreements: Analysis of 10 Project XL Case Studies. Science, Technology and Human Values, 30 (2), 223-250.

[13] Rahnema, S. (1992). Work Councils in Iran: The Illusion of Worker Control. Economic and Industrial Democracy, 13, 6992.

[14] Lizarralde, G., \& Massyn, M. (2008). Unexpected negative outcomes of community participation in low-cost housing projects in South Africa. Habitat International, 32, 1-14.

[15] Lotz-Sisitka, H., \& Burt, J. (2006). A critical review of participatory practice in integrated water resource management. Johannesburg: South Africa Water Resources Commission.

[16] Delanty, G. (1997). Habermas and Occidental Rationalism: The Politics of Identity, Social Learning, and the Cultural Limits of Moral Universalism. Sociological Theory, 15 (1), 30-59.

[17] Palerm, J. (2000). An Empirical-Theoretical Analysis Framework for Public Participation in Environmental Impact Assessment. Journal of Environmental Planning and Management, 43 (5), 581-600.

[18] USAID (2001). Policy Implementation: What USAID has learned, at http://www.usaid.gov/our. Accessed 8/10/2014.

[19] Stiglitz, J. (1998). Towards a New Paradigm for Development: Strategies, Policies, and Processes. Proceedings from the Prebisch Lecture at UNCTAD at https://ceaemgmt.colorado.edu accessed 08/10/2014.

[20] Bourne, L.; Walker, D. H. T. (2005). Visualizing stakeholder influence - two Australian examples. Project Management Journal 37 (1): 5-22. 
[21] Connor, D. M (2003). Preventing and Resolving Public Controversy. Commission of the European Communities. Brussels.

[22] Breggin, L. and Hallman, H. (1999). Building Capacity to Participate in Environmental Protection Agency Activities. Environmental Law Institute.

[23] Barkenbus, J. (1998). Expertise and the Policy Cycle. Energy, Environment and Resources Center. The University of Tennessee.

[24] Jergeas, G. F.; Williamson, E.; Skulmoski, G. J.; Thomas, J. L. (2000). Stakeholder management on Stakeholder management on construction projects. AACE International Transactions 12: $1-5$.

[25] Briner, W.; Hastings, C.; Geddes, M. (1996). Project Leadership Aldershot. Gower.

[26] Cleland, D. I (1995). Project management strategic design and implementation. McGraw-Hill, New York.

[27] Landin, A. (2000). Impact of Quality Management in the Swedish Construction process. PhD Thesis. Department of Construction Management. Lund University.

[28] Aaltonen, K.; Sivonen, R. 2009. Response strategies to stakeholder pressures in global projects. International Journal of Project Management 27: 131-141.

[29] E. L. I. Research Report. (1997). Transparency and Responsiveness: Building a Participatory Process for Activities Implemented Jointly Under the Climate Change Convention. Environmental Law Institute.
[30] Bisset, R. (2000). Methods of Consultation and Public Participation. EIA in Developing and Transitional Countries. John Wiley and Sons.

[31] Acland A. (2002). Guidelines for Stakeholder Dialogue. The Environment Council London.

[32] Petts, J. and Leach, B. (2000). Evaluating Methods for Public Participation: Literature Review. R \& D Technical Report E135. Environment Agency. UK.

[33] Yosie, T. F. and Herbst, T. D. (1998). Using Stakeholder Processes in Environmental Decision making. ICF Incorporated.

[34] Canter, L. W. (1996). Environmental Impact Assessment. McGraw Hill.

[35] Griffiths, A. (2000) New Organisational Architectures: creating and retrofitting for sustainability. Sustainability. Ed. Dunphy D. 226. Allen Unwin N. S. W. Australia.

[36] Kumar, R., (1999) Research methodology: A step by step guide for beginners, London, SAGE Publications.

[37] Jiang, J., Klein, G. (1999). Risks to different aspects of system success. Information and Management, 36 (5), 263-271.

[38] Lein, K. L. (2003). Integrated Environmental Planning. Blackwell Publication.

[39] C. E. Q. (1997). The National Environmental Policy Act. A Study of its Effectiveness after Twenty-Five Years. Council on Environmental Quality, http://ceq.eh.doe.gov. 